\title{
Mitteilungen UNION
}

Schweiz Z Ganzheitsmed 2013;25:254-255

DOI: 10.1159/000353729

\section{Zum Gedenken an Andreas Beck}

Ich glaube an die Zukunft dieser Zeit, aber wir müssen sie machen. (Albert Einstein)

Als $\mathrm{Du}$, verehrter Andi, noch unter uns weiltest, haben wir bei Unstimmigkeiten den «Hosenlupf» gedanklich durchgespielt; da hatte ich als Fliegengewicht gegen Dich keine Chance. Viele Jahre haben wir in der Kollegialen Instanz für Komplementärmedizin (KIKOM), die auch Dein Werk ist, zusammengearbeitet (Abb. 1). Zu den mittwöchigen Teamsitzungen kamst Du immer pünktlich, eine Tugend, die Du anlässlich aller Treffen beibehalten hast. Deine Vorlesungen waren gut ausformuliert und lagen in grossen Lettern ausgedruckt vor Dir, damit $\mathrm{Du}$ die Lesebrille nicht aufsetzen musstest; da stellte ich eine gewisse Eitelkeit bei Dir fest, die mich berührte. Die von Dir bevorzugten Tiere, nämlich die Elefanten, passten gut zu Dir, "Grosstiere» eben mit ausgeprägtem Appetit - bei Dir auf Veränderungen - und Sinn für gemeinsames Vorgehen.

Ein nachhallender Charakterzug war Deine Empathie zu Mitmenschen und Patienten im Besonderen, denen Du mit grossem Respekt begegnetest.

Und lasse ich Lorenz Fischer zu Wort kommen, dann formuliert er seine Gedanken an Dich folgendermassen:

Die Diskussionen mit Andi waren zeitweise nicht einfach, aber er hat es sich auch nicht einfach gemacht mit seinem totalen Engagement und unbändigem Kampf für die Sache. Dabei war er sehr hart im Argumentieren, aber immer gradlinig und ehrlich. Er hat nie ein Blatt vor den Mund genommen, «Smalltalk» gab es bei ihm nicht.

Trotz allem hatte er einen äusserst geistreichen Humor, auch in schwierigen Zeiten, politischen und für ihn gesundheitlichen.

Sein Kampf hat sich gelohnt, wenn wir sehen, was erreicht wurde.

Typisch auch, dass er bis zu seinem Tode weitergearbeitet hat. Pensionierung gab es für ihn nicht, die Neuraltherapie war sein Leben, und es musste so sein, dass er mitten aus der Arbeit heraus verstorben ist.

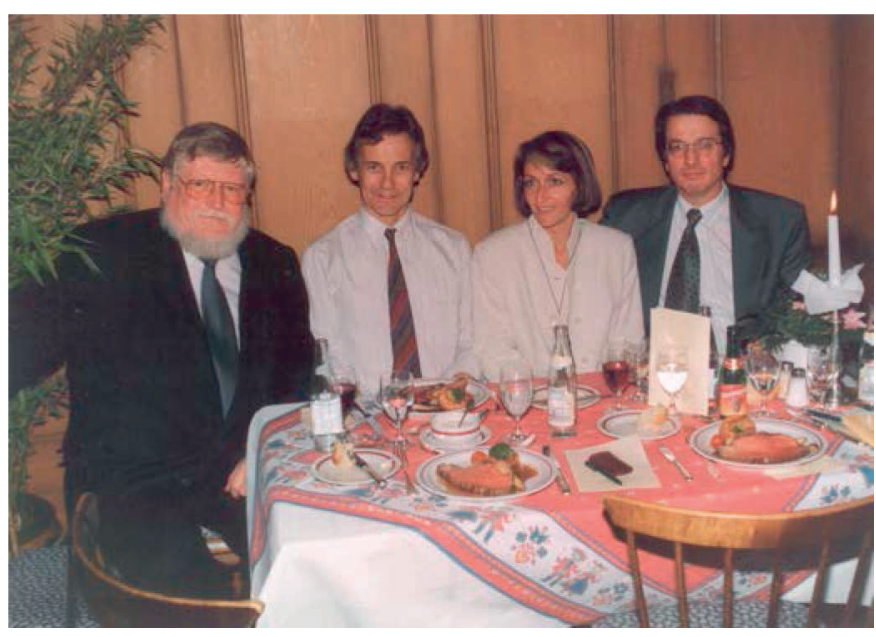

Abb. 1. 1996 in Interlaken beim SAGEM-Kongress; von links nach rechts: Andreas Beck, André Thurneysen, Brigitte Ausfeld, Peter Heusser - die ersten Dozenten der KIKOM.

Jedes Jahr haben wir einen Ausflug mit der gesamten KIKOM gemacht, unvergesslich ist der Tag am Murtensee, den Du organisiert hattest.

Im April 2001 hatten wir die Gelegenheit, die KIKOM in verschiedenen Beiträgen im Fernsehen (Telemed, ausgesendet in den Kantonen Aargau/Solothurn) vorzustellen. Du tatest Dich anfangs schwer mit dem Gedanken, als Filmstar aufzutreten. Dein Beitrag zur Entstehungsgeschichte der KIKOM war dann aber sehr gelungen und wurde während eines Jahres immer mal wieder ausgestrahlt, wie die anderen Beiträge zu den verschiedenen komplementärmedizinischen Methoden auch. (Die CD habe ich mir eben angeschaut, ach, waren wir da noch jung!)

Leider sind die Protokolle der Eidgenössischen Leistungskommission (ELK), in der wir jahrelang gemeinsam sassen, geheim, denn da könnte jedermann sich kundig machen, wie oft und auch wie vehement Du die Komple-
Vorstandssitzung UNION Vorstandssitzung UNION Vorstandssitzung UNION Vorstandssitzung UNION
Donnerstag, 29. August 2013 (Nachmittag)

Donnerstag, 17. Oktober 2013 (Nachmittag)

Donnerstag, 12. Dezember 2013 (Nachmittag/Abend)

Donnerstag, 3. April 2014 (Nachmittag) 
mentärmedizin gegenüber der Ignoranz einiger Kommissionsmitglieder verteidigt hast.

Und was die Zukunft betrifft, da liegt es nun an uns, den Zurückgebliebenen, Deinen Glauben an die Zukunft dieser Zeit (und der Komplementärmedizin) weiter zu tragen. Ich danke Dir für Dein Engagement, das so viel Positives hervorgebracht hat, auch wenn der Umgang mit Dir - zwar selten, aber immerhin - ganz schön schwierig sein konnte; bereichernd war er allemal.

Dr. med. Brigitte Ausfeld-Hafter

Em. Dozentin der KIKOM, Universität Bern

PS: Die Idee zu diesem Text entstand anlässlich der Delegiertenversammlung der UNION am 25. April 2013 in Lausanne. Hansueli Albonico als Präsident liess uns
Anwesende Erinnerungen an Andi Beck erzählen. Es wurde dann beschlossen, mir die schriftliche Fassung meiner Gedanken zu überlassen. Nach der Durchsicht des Texts durch Hansueli Albonico, Bruno Ferroni und MarieAnne Stettbacher und der Einbindung der Worte von Lorenz Fischer möchte ich jetzt Sie, verehrter Leser, bitten, meine Worte mit Wohlwollen anzusehen. Denn unüblich sind meine Formulierungen, lesen wir doch meist de mortuis nisi nihil bene. Leser! Bedenke, dass ich Andi Becks Schwächen und seine Stärken mit dem ihm gebührenden Respekt in guter Erinnerung behalte.

Ein ausführlicher Bericht über das Leben und das Schaffen von Andreas Beck, verfasst von Dr. med. dent. MarieAnne Stettbacher, ist in der Schweizerischen Ärztezeitung erschienen (2013;94:501). 